\title{
Postoperative Radiochemotherapy Using Modern Radiotherapy Techniques in Elderly Patients with Head and Neck Squamous Cell Carcinoma: The Challenge of Weighing Up Benefits and Harms of Treatment Modalities in Clinical Practice
}

\author{
Martin Leu ${ }^{1}$, Christoph Patzer ${ }^{1}$, Manuel Guhlich ${ }^{1}$, Jacqueline Possiel ${ }^{1}$, Yiannis Pilavakis ${ }^{2}$, \\ Markus Anton Schirmer ${ }^{1}$ (D), Stefan Rieken ${ }^{1}$ and Leif Hendrik Dröge ${ }^{1, *}$
}

1 Department of Radiotherapy and Radiation Oncology, University Medical Center Göttingen, Robert-Koch-Str. 40, 37075 Göttingen, Germany; martin.leu@med.uni-goettingen.de (M.L.); christoph.patzer@stud.uni-goettingen.de (C.P.); manuel.guhlich@med.uni-goettingen.de (M.G.); jacqueline.possiel@med.uni-goettingen.de (J.P.); mschirmer@med.uni-goettingen.de (M.A.S.); stefan.rieken@med.uni-goettingen.de (S.R.)

2 Department of Otorhinolaryngology, University Medical Center Göttingen, 37075 Göttingen, Germany; yiannis.pilavakis@med.uni-goettingen.de

check for updates

Citation: Leu, M.; Patzer, C.; Guhlich, M.; Possiel, J.; Pilavakis, Y.; Schirmer, M.A.; Rieken, S.; Dröge, L.H. Postoperative Radiochemotherapy Using Modern Radiotherapy Techniques in Elderly Patients with Head and Neck Squamous Cell Carcinoma: The Challenge of Weighing Up Benefits and Harms of Treatment Modalities in Clinical Practice. Cancers 2021, 13, 3384. https://doi.org/10.3390/ cancers13143384

Academic Editor: Primož Strojan

Received: 23 April 2021

Accepted: 2 July 2021

Published: 6 July 2021

Publisher's Note: MDPI stays neutral with regard to jurisdictional claims in published maps and institutional affiliations.

Copyright: (c) 2021 by the authors. Licensee MDPI, Basel, Switzerland. This article is an open access article distributed under the terms and conditions of the Creative Commons Attribution (CC BY) license (https:/ / creativecommons.org/licenses/by/ $4.0 /)$.
* Correspondence: hendrik.droege@med.uni-goettingen.de; Tel.: +49-551-3964505

Simple Summary: Locally advanced head and neck squamous cell carcinomas (HNSCC) are often managed with surgery and postoperative radiochemotherapy (RCT). Until now, a deeper understanding of specific management strategies for elderly patients was lacking. In the present study, we compared patients $\geq 70$ years of age and younger patients treated with postoperative RCT for HNSCC. All patients were treated with modern radiotherapy techniques (IMRT/VMAT). Elderly patients had more comorbidities. In addition, they less frequently received concomitant systemic treatment. The rates of mucositis and dermatitis were lower in patients $\geq 70$ years. Elderly patients had significantly worse overall survival and progression-free survival. Locoregional and distant control were comparable in elderly and younger patients. In conclusion, postoperative radiochemotherapy is a safe and effective treatment option in patients $\geq 70$ years. In light of comorbidities and poor survival rates, potential benefits and harms of radiotherapy and concomitant systemic treatment should be weighed carefully for this age group.

Abstract: Locally advanced head and neck squamous cell carcinomas (HNSCC) are often managed with surgery followed by postoperative radiochemotherapy (RCT). With the general increase in life expectancy, the proportion of elderly patients with HNSCC is expected to grow rapidly. Until now, a deeper understanding of specific management strategies for these patients in clinical routine was lacking. In the present study, we compared elderly patients ( $\geq 70$ years, $n=52)$ and younger patients $(n=245)$ treated with postoperative RCT for HNSCC at our tertiary cancer center. All patients were irradiated with modern radiotherapy techniques (IMRT/VMAT). Patients $\geq 70$ years of age had more comorbidities. Additionally, elderly patients less frequently received concomitant systemic treatment. The rates of mucositis and dermatitis were lower in patients $\geq 70$ years. Elderly patients had significantly worse overall and progression-free survival. Locoregional and distant control were comparable in elderly and younger patients. In conclusion, postoperative RCT is a safe and effective treatment option in patients $\geq 70$ years. In light of comorbidities and poor overall survival rates, benefits and harms of radiotherapy and concomitant systemic treatment should be weighed carefully. When exclusively applying up-to-date radiotherapy techniques with, at the same time, careful use of concomitant systemic therapy, favorable acute toxicity profiles are achieved.

Keywords: head and neck; squamous cell cancer; postoperative treatment; radiochemotherapy; elderly patients; geriatric oncology; comorbidities; acute toxicity; late toxicity; survival 


\section{Introduction}

Head and neck squamous cell carcinomas (HNSCC) caused 450,000 deaths worldwide in 2018 [1]. The incidence is rising and an increase of 30\% is predicted until 2030 [1]. Locally advanced HNSCC are often managed with intensive multimodal treatment, including surgery followed by postoperative radiochemotherapy (RCT) [2-4]. Nevertheless, longterm outcomes remain poor, with 10-year overall survival and disease-free survival rates of less than $30 \%$ [5]. At the same time, local treatment is associated with high rates of acute and long-term morbidity [6-8].

In elderly patients, HNSCC are rare [9]. Less than $20 \%$ of the HNSCC patients are $>70$ years of age [9]. At the same time, regarding the general increase of life expectancy, the proportion of elderly patients with HNSCC is expected to grow rapidly $[1,10]$. In the major clinical trials on treatment strategies in HNSCC, these patients were either excluded or were underrepresented $[3,4,11]$. This is the case for earlier trials which established the indications for postoperative RCT as well as for contemporary prospective trials on treatment strategies in HNSCC [3,4,11,12]. Recently, several mostly retrospective studies focused on outcomes in elderly patients and found evidence that specific management approaches are absolutely needed [13-15]. Nevertheless, until now, a deeper understanding of the implications of the findings for clinical routine was lacking [15].

In the present study, we analyzed patients treated with postoperative RCT for HNSCC at our tertiary cancer center. We compared baseline characteristics, treatment-associated toxicities, and outcomes between elderly patients $\geq 70$ years of age and patients $<70$ years of age in a modern cohort. All patients were treated with either conventional intensitymodulated radiotherapy (IMRT) or volumetric modulated arc therapy (VMAT).

\section{Patients and Methods}

\subsection{Patient Cohort}

We retrospectively reviewed our clinic's medical records for patients treated with postoperative RCT for non-metastatic HNSCC. Patients were included beginning in 05/2008, when new linear accelerators were installed and treatment with IMRT/VMAT was standardly used in our radiotherapy department. Before surgery, all patients underwent staging examinations (CT scan of the head and neck, endoscopic head and neck examination, chest $\mathrm{X}$-ray and abdominal ultrasound or CT examination of thorax and abdomen). The oncological strategies were discussed (both pre- and post-surgery) in the local multidisciplinary tumor board consisting of experienced radiation oncologists, head and neck surgeons, neuroradiologists, and pathologists. The procedures were performed in accordance with the guidelines [16-19]. This retrospective study was conducted after authorization by the local ethics committee (University Göttingen Medical Center, number 6/1/21).

\subsection{Radiotherapy}

Postoperative radiotherapy was standardly performed in patients with $\geq \mathrm{pT} 3, \mathrm{pN}+$, or $\mathrm{R} 1$ tumors [16-19]. In addition, postoperative radiotherapy was discussed on an individual basis if other risk factors were present (e.g., L1, V1 status, patients with single positive lymph nodes without extracapsular extension, patients with recurrent disease) [16-19]. Beschel et al. previously described the radiotherapy procedures [20]. Before radiotherapy, patients received a comprehensive dental evaluation by the University Medical Center dentists. Here, a dental splint was individually adapted. Patients underwent planning CT scans of the head and neck region with customized thermoplastic masks. The clinical target volume included the primary tumor region and the neck. The contours were generated based on the respective guidelines [21-23]. The planning target volume was generated using a $10 \mathrm{~mm}$ margin in all directions. All patients were treated either with conventional IMRT or with VMAT (RapidArc ${ }^{\circledR}$, Varian Medical Systems, Palo Alto, CA, USA) with daily on-board imaging. Treatment plans were calculated using Eclipse (Varian Medical Systems, Palo Alto, CA, USA). The organs at risk constraints were used according to the QUANTEC recommendations [24-26]. 


\subsection{Concomitant Systemic Treatment}

The procedures in systemic treatment were already described previously $[20,27,28]$. Concomitant systematic treatment was standardly applied in patients with extracapsular extension and R1 tumors. Additionally, patients were treated with concomitant chemotherapy in case of further risk factors (e.g., $\geq 2$ positive lymph nodes, UICC stages III-IV). The decision was left at the discretion of the individual treating physician [2-4]. The pre-treatment examinations were a complete blood cell count with clinical chemistry, an electrocardiogram, an audiometry test and a creatinine clearance from a $24 \mathrm{~h}$ urine collection. In patients with creatinine clearance of $60-<70 \mathrm{~mL} / \mathrm{min}$, concomitant cisplatin was used with strict indication. In cases with creatinine clearance of $<60 \mathrm{~mL} / \mathrm{min}$, cisplatin was omitted. The cisplatin regimen (e.g., weekly or daily) was set by the treating physician on an individual basis. In cases with contraindications against cisplatin, cetuximab was applied according to the schedule by Bonner et al. [29].

\subsection{Follow-Up Procedures and Toxicity Scoring}

Patients who received concomitant chemotherapy were hospitalized for the RCT initiation. A minimum of weekly visits with assessment of toxicities were performed during RCT; including a complete blood cell count and an assessment of clinical chemistry. The toxicities were scored in accordance with the CTCAE criteria v5.0 (acute toxicities, [30]) and in accordance with the LENT/SOMA criteria (late toxicities, [31]). After RCT, follow-up with anamnesis and clinical examination was performed in 18-month intervals for a total of 5 years. Additionally, patients regularly presented to the treating head and neck surgeon.

\subsection{Statistics}

The software SPSS (v. 26) was used for data administration and statistical analysis. The survival curves were generated and compared with log-rank test using the software ' $\mathrm{R}$ ' (v. 4.0.2, plugin 'KMWin' [32]). The chi-square test and the Mann-Whitney U test were applied when comparing baseline and RCT characteristics for patients $\geq 70$ years vs. $<70$ years of age and for the comparison of patients $\geq 70$ years of age who underwent radiotherapy alone vs. RCT. The survival times were counted from the day of histopathological tumor diagnosis. We evaluated overall survival (OS; event: patient death due to any cause), progression-free survival (PFS; events: patient death due to any cause and any tumor progression), time to recurrence (TTR; events: local, regional or distant tumor progression, death due to HNSCC), locoregional control (LRC; events: local or regional tumor progression), and distant control (DC; event: occurrence of distant metastases).

\section{Results}

\subsection{Patient and Tumor Characteristics}

In total, we included 297 consecutive patients. The cut-off for the definition of 'elderly patients' was set at the age of 70 years. This cut-off has been reported to be most frequently used in geriatric oncology and to have clinical relevance $[33,34]$. In the whole cohort, 245 patients $(82.5 \%)$ were younger than 70 years and 52 patients $(17.5 \%)$ were older than or equal to 70 years old. Patients were treated from May 2008 to November 2019. The median age was 60.0 years (range, 23.0-85.0 years). The median follow-up was 37.0 months (range, 3.0-147.0 months). When comparing the treatment groups, patients $\geq 70$ years of age had more comorbidities and fewer tumors with nodal involvement. Please see Table 1 for further details. 
Table 1. Patient and tumor characteristics. For each parameter, either the number and percentage or the median and range are given. For comparison of treatment groups, we used the chi-square test.

\begin{tabular}{|c|c|c|c|}
\hline Characteristics & $\begin{array}{c}\text { Age },<70 \text { Years } \\
(n=245)\end{array}$ & $\begin{array}{c}\text { Age }, \geq 70 \text { Years } \\
(n=52)\end{array}$ & $p$-Value \\
\hline Age (years) & $58(23-69)$ & $73(70-85)$ & - \\
\hline Sex & & & 0.52 \\
\hline Female & $47(19.2)$ & $8(15.4)$ & \\
\hline Male & $198(80.8)$ & $44(84.6)$ & \\
\hline Charlson Comorbidity Index & & & $<0.01$ \\
\hline $0-3$ & $125(51.0)$ & $0(0.0)$ & \\
\hline $4-7$ & $119(48.6)$ & $51(98.1)$ & \\
\hline $8-10$ & $1(0.4)$ & $1(1.9)$ & \\
\hline Tumor localization & & & 0.26 \\
\hline Hypopharynx & $47(19.2)$ & $6(11.5)$ & \\
\hline Larynx & $37(15.1)$ & $13(25.0)$ & \\
\hline Oral cavity & $85(34.7)$ & $18(34.6)$ & \\
\hline Oropharynx & $76(31.0)$ & $15(28.8)$ & \\
\hline HPV status & & & 0.63 \\
\hline Positive & $21(27.6)$ & $3(20.0)$ & \\
\hline Negative & $29(38.2)$ & $6(40.0)$ & \\
\hline Undetermined & $26(34.2)$ & $6(40.0)$ & \\
\hline Grading & & & 0.76 \\
\hline G1 & $9(3.7)$ & $1(1.9)$ & \\
\hline G2 & $193(78.8)$ & $41(78.8)$ & \\
\hline $\mathrm{G} 3$ & $41(16.7)$ & $10(19.2)$ & \\
\hline Undetermined & $2(0.8)$ & $0(0.0)$ & \\
\hline pT status & & & 0.09 \\
\hline T0 & $5(2.0)$ & $4(7.7)$ & \\
\hline $\mathrm{T} 1$ & $38(15.5)$ & $6(11.5)$ & \\
\hline $\mathrm{T} 2$ & $61(24.9)$ & $12(23.1)$ & \\
\hline T3 & $85(34.7)$ & $13(25.0)$ & \\
\hline $\mathrm{T} 4$ & $56(22.9)$ & $17(32.7)$ & \\
\hline $\mathrm{pN}$ status & & & $<0.01$ \\
\hline N0 & $56(22.9)$ & $24(46.1)$ & \\
\hline N1 & $55(22.4)$ & $8(15.4)$ & \\
\hline N2 & $119(48.6)$ & $8(15.4)$ & \\
\hline N3 & $15(6.1)$ & $12(23.1)$ & \\
\hline Presence of ECE & & & 0.36 \\
\hline Yes & $64(34.0)$ & $12(42.9)$ & \\
\hline AJCC classification (8th edition, 2017) ${ }^{1}$ & & & 0.86 \\
\hline $\mathrm{I}^{1}$ & $18(7.3)$ & $3(5.8)$ & \\
\hline II $^{1}$ & $16(6.5)$ & $5(9.6)$ & \\
\hline III & $75(30.6)$ & $15(28.8)$ & \\
\hline IV & $136(55.5)$ & $29(55.8)$ & \\
\hline Resection status & & & 0.59 \\
\hline R0 & 235 (95.9) & $49(94.2)$ & \\
\hline $\mathrm{R} 1$ & $10(4.1)$ & $3(5.9)$ & \\
\hline
\end{tabular}

${ }^{1}$ In this study, the medical records were retrospectively reviewed and the AJCC stages were updated and harmonized according to the current 8th edition, including the classifications for HPV negative and HPV positive tumors. Consequently, 20 patients with HPV positive tumors were downstaged from the former classification which was applied for the treatment indications. Another 20 patients with stage I-II disease underwent surgery for recurrent tumors and subsequently underwent postoperative treatment. In 2 patients with stage I-II disease, the postoperative treatment was undertaken based on a discrepancy between initial clinical staging (cT3) and pathological staging (pT2) after transoral laser microsurgery.

\subsection{Radiochemotherapy}

All patients were treated with IMRT $(n=126,42.4 \%)$ or VMAT $(n=171,57.6 \%)$. Both the median planned and administered radiotherapy doses were 64.0 Gy (range, 54.0-66.0 Gy and 38.0-66.0 Gy). In detail, the planned radiotherapy doses in 182 patients were $64 \mathrm{~Gy}(n=178)$ or $66 \mathrm{~Gy}(n=4)$ with simultaneous irradiation of primary tumor region 
(2.0 Gy/fraction, 30 fractions), affected lymph node regions (1.92 Gy/fraction, 30 fractions), and elective nodes ( $1.8 \mathrm{~Gy} /$ fraction, 30 fractions), followed by a sequential boost of $2^{*} 2 \mathrm{~Gy}$ $(n=178)$ or $3^{*} 2 \mathrm{~Gy}(n=4)$ to the primary tumor. The planned dose in 112 patients was 62.4 Gy with simultaneous irradiation of primary tumor region (2.08 Gy/fraction, 30 fractions), affected lymph node regions (1.92 Gy/fraction, 30 fractions), and elective nodes (1.8 Gy/fraction, 30 fractions). In one patient, the planned dose was $63.0 \mathrm{~Gy}$ (simultaneous irradiation of primary tumor region/affected lymph node regions up to $57.6 \mathrm{~Gy}$ in 30 fractions [1.92 Gy/fraction] and irradiation of elective nodes up to $54 \mathrm{~Gy}$ in 30 fractions [1.8 Gy/fraction], followed by a sequential boost with $3^{*} 1.8$ Gy to the primary tumor region). One patient had a planned dose of $60.0 \mathrm{~Gy}$ (30 fractions of $2 \mathrm{~Gy} /$ fraction to the primary tumor region and $54 \mathrm{~Gy}$ [1.8 Gy/fraction] to the neck). In one patient, the planned dose to the primary tumor region and to the neck was $54 \mathrm{~Gy}$ in $1.8 \mathrm{~Gy}$ fractions. A total of 282 patients $(94.9 \%)$ completed radiotherapy as prescribed. In the whole study cohort, a concomitant systemic treatment was given in 223 patients (75.1\%). Elderly patients less frequently received a concomitant systemic treatment. Additionally, the percentage of patients $\geq 70$ years receiving cetuximab instead of cisplatin was higher compared to younger patients. Please see Table 2 for further details.

Table 2. Treatment characteristics. For each parameter, either the number and percentage or the median and range are given. For comparison of treatment groups, we used the chi-square test* or the Mann-Whitney U test\#.

\begin{tabular}{|c|c|c|c|}
\hline Characteristics & $\begin{array}{c}\text { Age, }<70 \text { Years } \\
(n=245)\end{array}$ & $\begin{array}{c}\text { Age, } \geq 70 \text { Years } \\
(n=52)\end{array}$ & $p$-Value \\
\hline \multicolumn{4}{|l|}{ Radiotherapy } \\
\hline Technique & & & $0.77 *$ \\
\hline VMAT & $142(58.0)$ & $29(55.8)$ & \\
\hline IMRT & $103(42.0)$ & $23(44.2)$ & \\
\hline Dose, planned [Gy] & $\begin{array}{c}64.0 \\
(54.0-66.0)\end{array}$ & $\begin{array}{c}64.0 \\
(62.4-66.0)\end{array}$ & $0.47 \#$ \\
\hline Dose, administered [Gy] & $\begin{array}{c}64.0 \\
(38.0-66.0)\end{array}$ & $\begin{array}{c}64.0 \\
(54.0-64.0)\end{array}$ & $0.33 \#$ \\
\hline Dose received & & & $0.28 *$ \\
\hline $100 \%$ of planned dose & $231(94.3)$ & $51(98.1)$ & \\
\hline$\geq 80-<100 \%$ of planned dose & $11(4.5)$ & $1(1.9)$ & \\
\hline$<80 \%$ of planned dose & $3(1.2)$ & $0(0.0)$ & \\
\hline $\begin{array}{l}\text { Interruptions/breaks } \\
\text { Systemic treatment }\end{array}$ & $117(47.8)$ & $29(55.8)$ & $0.29 *$ \\
\hline $\begin{array}{l}\text { Received concomitant } \\
\text { systemic treatment }\end{array}$ & $192(78.4)$ & $31(59.6)$ & $0.04 *$ \\
\hline Received $<100 \%$ of planned dose & $72(37.5)$ & $17(54.8)$ & $0.07 *$ \\
\hline $\begin{array}{l}\text { Systemic treatment type } \\
\text { Cetuximab }\end{array}$ & $3(1.2)$ & $3(9.7)$ & $<0.01$ * \\
\hline $\begin{array}{l}\text { Cetuximab } \\
\text { Cisplatin }\end{array}$ & $189(98.8)$ & $28(90.3)$ & \\
\hline Cisplatin regimen & & & $0.51 *$ \\
\hline $6 \mathrm{mg} / \mathrm{m}^{2} / \mathrm{d}$ daily & $116(61.4)$ & $14(50.0)$ & \\
\hline $20 \mathrm{mg} / \mathrm{m}^{2} / \mathrm{d} 1-5$ ( 2 cycles $)$ & $0(0.0)$ & $1(3.6)$ & \\
\hline $40 \mathrm{mg} / \mathrm{m}^{2} / \mathrm{d}$ weekly & $73(38.6)$ & $13(46.4)$ & \\
\hline
\end{tabular}

\subsection{Toxicities}

In the whole study cohort, $167 / 297$ patients $(56.2 \%)$ experienced acute organ toxicities $\geq$ grade 3 . We observed $\geq$ grade 3 mucositis in $32 / 297$ patients $(10.8 \%)$, $\geq$ grade 3 dermatitis in $7 / 297$ patients (2.4\%), and $\geq$ grade 3 dysphagia in $156 / 297$ patients (52.5\%). Hematologic toxicities of $\geq$ grade 3 were documented in $73 / 297$ patients $(24.6 \%)$. Late toxicities $\geq$ grade 3 were registered in $34 / 267$ patients $(12.7 \%$, information on late toxicity missing in 30 patients). When comparing patients $\geq 70$ years of age vs. $<70$ years of age, elderly patients experienced mucositis and dermatitis (grades 1-4) less frequently. There 
were no differences in the rates of high-grade ( $\geq$ grade 3 ) mucositis and dermatitis between the age groups. Please see Table 3 for further details. Additionally, in patients $\geq 70$ years of age, there were no differences in acute and late toxicities between patients who received radiotherapy alone and patients who received RCT (Supplementary Table S1).

Table 3. Toxicities. The CTCAE criteria and the LENT/SOMA criteria were used for the evaluation of acute and late toxicities. For each parameter, the number and percentage are given. For comparison of treatment groups, we used the chi-square test. * The information on late toxicity is missing in 30 patients.

\begin{tabular}{|c|c|c|c|}
\hline Toxicities & $\begin{array}{c}\text { Age },<70 \text { Year } \\
\quad(n=245)\end{array}$ & $\begin{array}{l}\text { Age, } \geq 70 \text { Years } \\
\quad(n=52)\end{array}$ & $p$-Value \\
\hline \multicolumn{4}{|l|}{ Acute organ toxicity } \\
\hline Mucositis & & & 0.03 \\
\hline 0 & $13(5.3)$ & $9(17.3)$ & \\
\hline 1 & $57(23.3)$ & $14(26.9)$ & \\
\hline 2 & $148(60.4)$ & $24(46.2)$ & \\
\hline 3 & $25(10.2)$ & $5(9.6)$ & \\
\hline 4 & $2(0.8)$ & $0(0.0)$ & \\
\hline$\geq$ grade 3 & $27(11.0)$ & $5(9.6)$ & 0.91 \\
\hline Dermatitis & & & $<0.01$ \\
\hline 0 & $6(2.4)$ & 7 (13.5) & \\
\hline 1 & $133(54.3)$ & $29(55.8)$ & \\
\hline 2 & $100(40.8)$ & $15(28.8)$ & \\
\hline 3 & $6(2.4)$ & $1(1.9)$ & \\
\hline$\geq$ grade 3 & $6(2.4)$ & $1(1.9)$ & 0.82 \\
\hline Dysphagia & & & 0.23 \\
\hline 0 & $29(11.8)$ & $4(7.7)$ & \\
\hline 1 & $41(16.7)$ & $5(9.6)$ & \\
\hline 2 & $48(19.6)$ & $14(26.9)$ & \\
\hline 3 & $118(48.2)$ & $29(55.8)$ & \\
\hline 4 & $9(3.7)$ & $0(0.0)$ & \\
\hline$\geq$ grade 3 & $127(52.2)$ & $29(55.8)$ & 0.64 \\
\hline Received feeding tube before RCT & $64(26.1)$ & $19(36.5)$ & 0.13 \\
\hline Received feeding tube during RCT & $65(26.5)$ & $15(28.8)$ & 0.73 \\
\hline $\begin{array}{c}\text { Overall acute organ toxicity, } \geq \text { grade } 3 \\
\text { Hematologic toxicity }\end{array}$ & $137(55.9)$ & $30(57.7)$ & 0.82 \\
\hline Overall hematologic toxicity, $\geq$ grade 3 & $62(25.3)$ & $11(21.2)$ & 0.53 \\
\hline Anemia, $\geq$ grade 3 & $6(2.4)$ & $2(3.8)$ & 0.57 \\
\hline Leukopenia, $\geq$ grade 3 & $55(22.4)$ & $10(19.2)$ & 0.61 \\
\hline Thrombopenia, $\geq$ grade 3 & $10(4.1)$ & $0(0.0)$ & 0.59 \\
\hline Overall late toxicity, $\geq$ grade $2 *$ & $90(40.5)$ & $17(37.8)$ & 0.73 \\
\hline Overall late toxicity, $\geq$ grade $3 *$ & $31(14.0)$ & $3(6.7)$ & 0.18 \\
\hline
\end{tabular}

\subsection{Survival}

In the whole cohort, the five-year overall survival (OS), progression-free survival (PFS), time to recurrence (TTR), locoregional control (LRC), and distant control (DC) were: 61.7\%, $53.4 \%, 65.1 \%, 80.2 \%$, and $81.6 \%$. Patients $\geq 70$ years experienced significantly worse OS and PFS (Figures 1 and 2). There were no differences in TTR, LRC and DC (Figures 3-5). During follow-up, locoregional recurrence occurred in 39/297 patients (14.1\%). The locoregional recurrences were isolated primary tumor recurrences $(n=27$ patients) and recurrences in the head and neck region outside the primary tumor site ( $n=12$ patients). Distant metastases were registered in $42 / 297$ patients (14.1\%). The metastases were localized in liver ( $n=3$ patients), lung ( $n=24$ patients), bone ( $n=9$ patients), and cerebrum ( $n=6$ patients). Additionally, in patients $\geq 70$ years of age, there were no differences between patients who received radiotherapy alone vs. patients who received RCT (OS, TTR and LRC; Supplementary Figures S1-S3). 


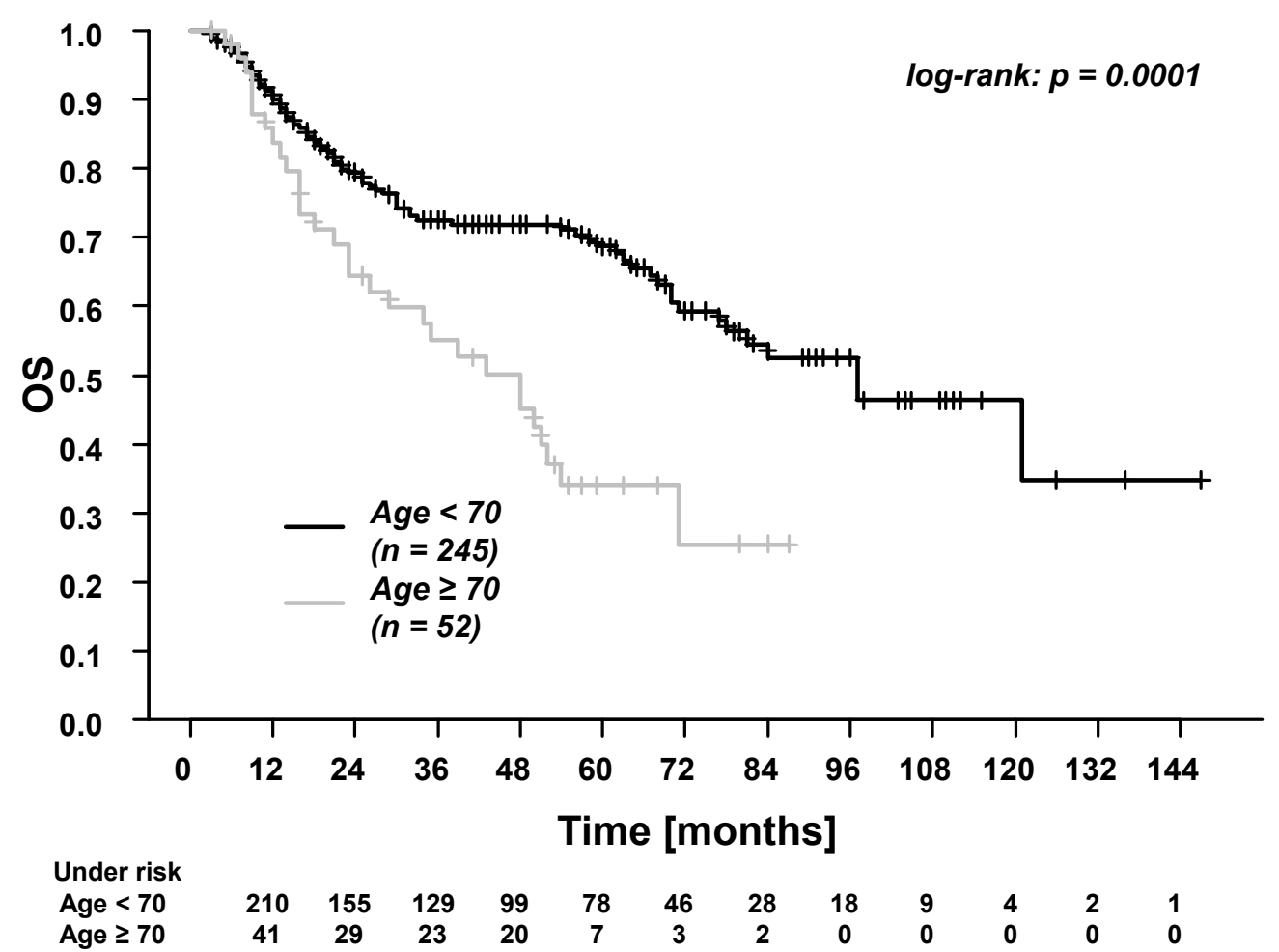

Figure 1. Overall survival (OS) for patients $<70$ years vs. patients $\geq 70$ years of age. The 3 -year and 5-year OS for patients $<70$ years were $72.5 \%$ and $68.7 \%$. The 3-year and 5 -year OS for patients $\geq 70$ years were $55.2 \%$ and $33.8 \%$.

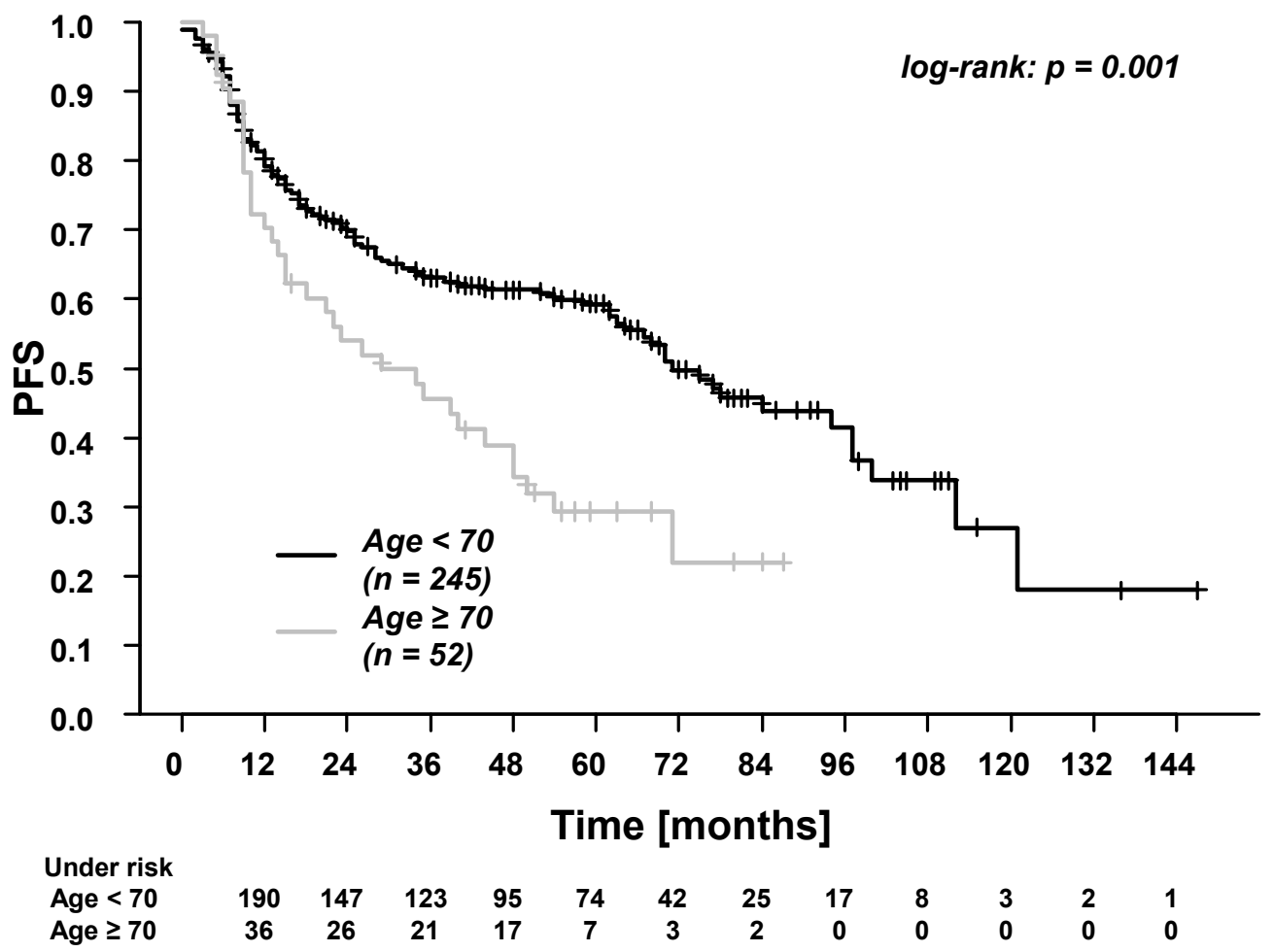

Figure 2. Progression-free survival (PFS) for patients $<70$ years vs. patients $\geq 70$ years of age. The 3 -year and 5-year PFS for patients $<70$ years were $63.0 \%$ and $59.2 \%$. The 3-year and 5-year PFS for patients $\geq 70$ years were $45.3 \%$ and $29.4 \%$. 


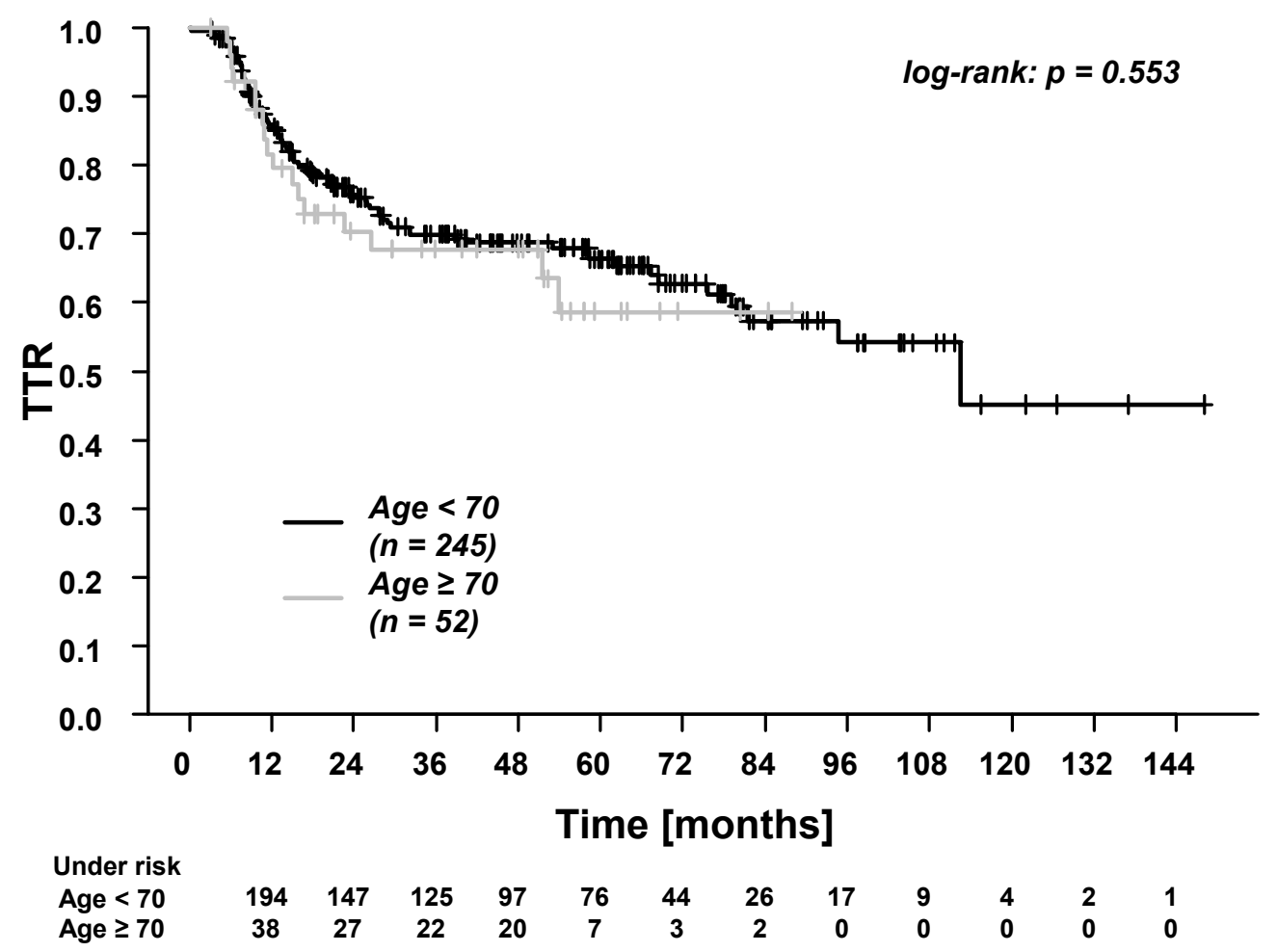

Figure 3. Time to recurrence (TTR) for patients $<70$ years vs. patients $\geq 70$ years of age. The 3-year and 5-year TTR for patients $<70$ years were $69.9 \%$ and $66.3 \%$. The 3-year and 5-year TTR for patients $\geq 70$ years were $67.7 \%$ and $58.6 \%$.
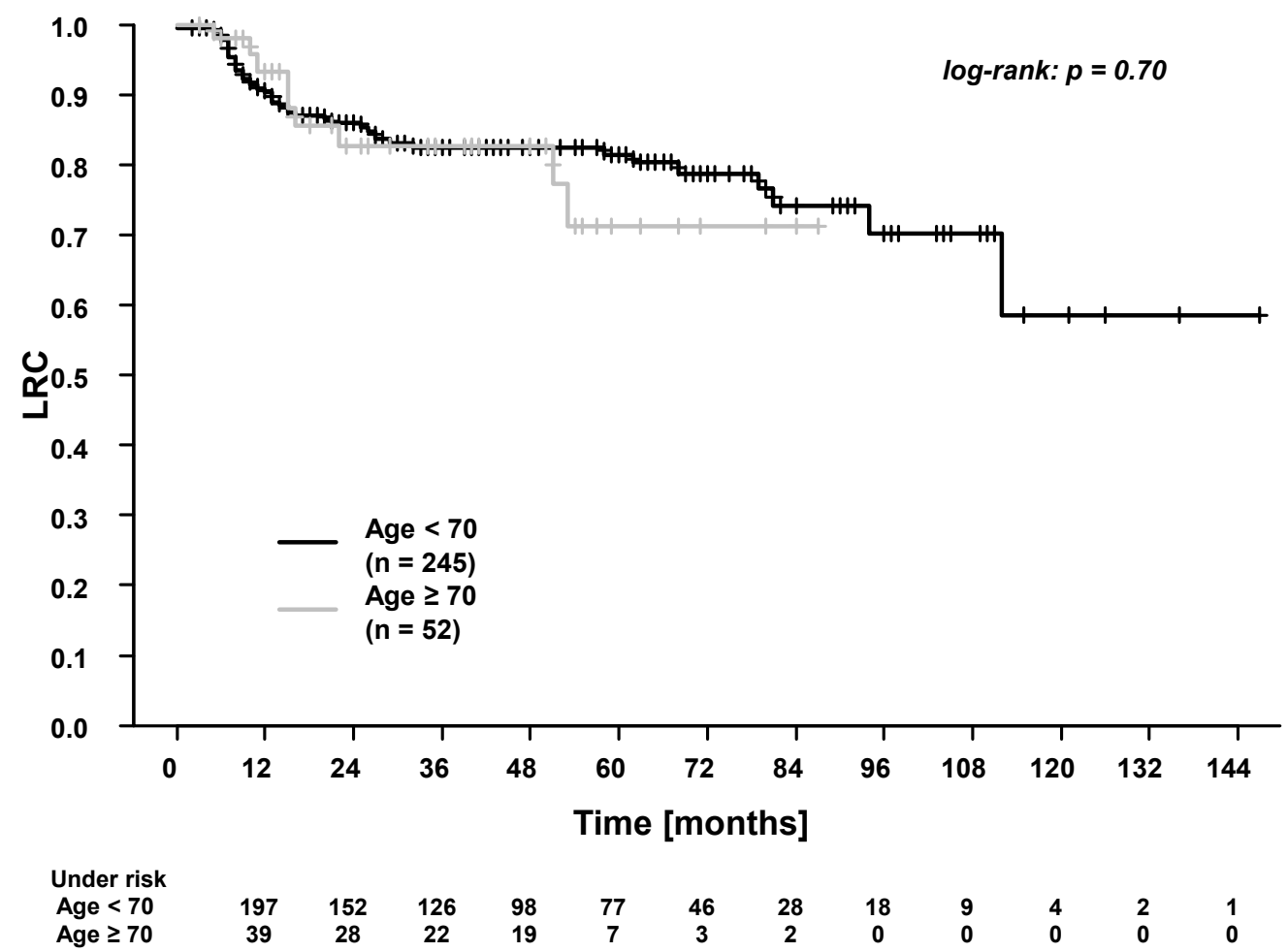

Figure 4. Locoregional control (LRC) for patients $<70$ years vs. patients $\geq 70$ years of age. The 3-year and 5-year LRC for patients $<70$ years were $82.7 \%$ and $81.5 \%$. The 3-year and 5-year LRC for patients $\geq 70$ years were $82.7 \%$ and $71.2 \%$. 


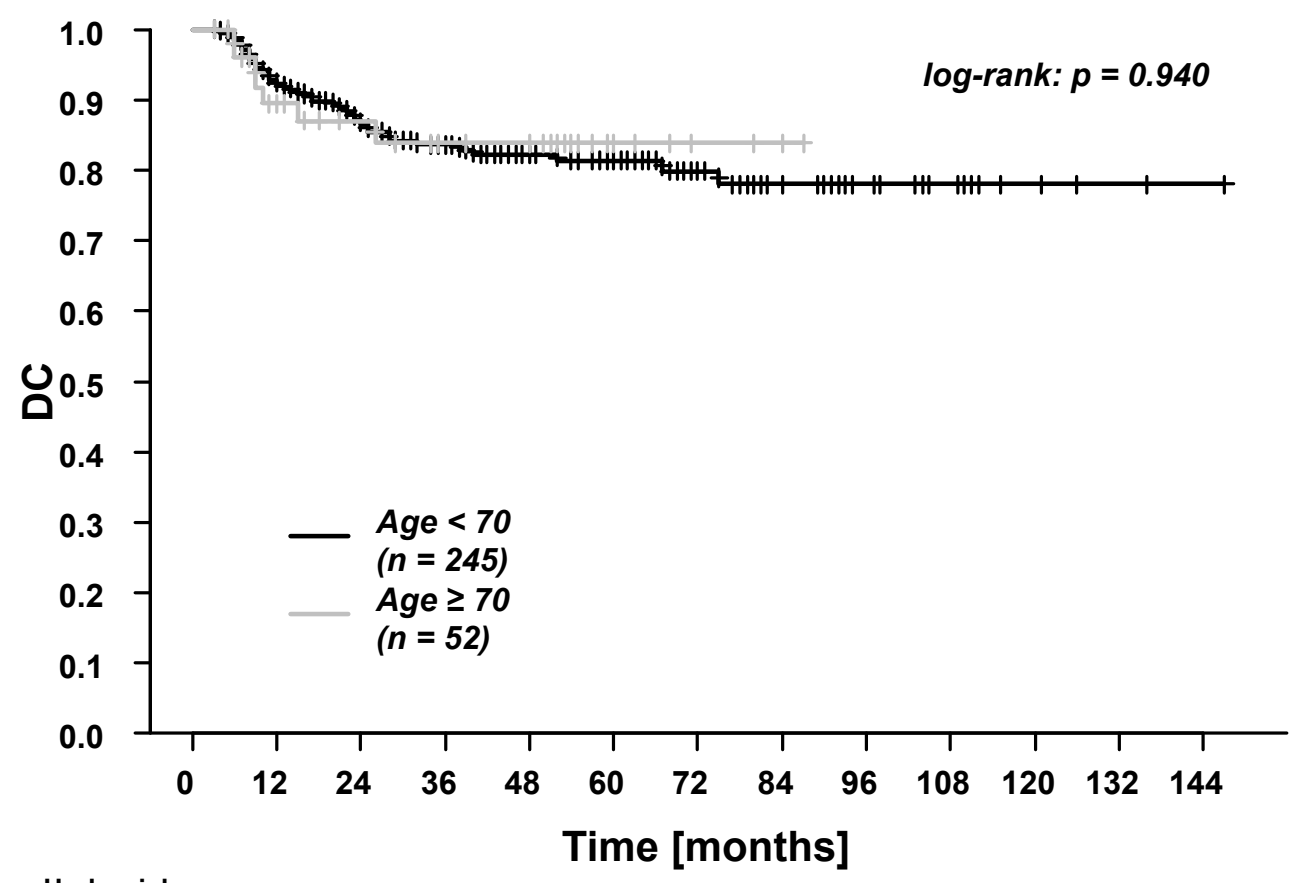

$\begin{array}{lcccccccccccc}\text { Under risk } & & & & & & & & & & & & \\ \text { Age }<70 & 202 & 153 & 130 & 99 & 78 & 45 & 27 & 17 & 9 & 4 & 2 & 1 \\ \text { Age } \geq 70 & 38 & 28 & 22 & 21 & 8 & 3 & 2 & 0 & 0 & 0 & 0 & 0\end{array}$

Figure 5. Distant control (DC) for patients $<70$ years vs. patients $\geq 70$ years of age. The 3 -year and 5 -year DC for patients $<70$ years were $83.6 \%$ and $81.4 \%$. The 3-year and 5 -year DC for patients $\geq 70$ years were both $83.9 \%$.

\section{Discussion}

In elderly patients, HNSCC are rare [9]. Less than $20 \%$ of HNSCC patients get diagnosed at the age of $>70$ years [9]. At the same time, regarding the general increase in life expectancy, the proportion of elderly patients with HNSCC is expected to grow rapidly $[1,10]$. Recently, several mostly retrospective studies focused on outcomes in elderly HNSCC patients and found evidence that specific management strategies are absolutely needed [13-15]. Nevertheless, until now, a deeper understanding of the implications of the findings for clinical routine was lacking [15]. In the present study, we analyzed patients treated with postoperative RCT for HNSCC at our tertiary cancer center. We compared baseline characteristics, treatment-associated toxicities, and outcomes between elderly patients $\geq 70$ years of age and patients $<70$ years of age.

Firstly, we found no difference in locoregional control (LRC, five-year overall rate of $80.2 \%$ ) between patients $<70$ years and patients $\geq 70$ years of age. Additionally, there were no differences in radiotherapy completion rates, with $>95 \%$ of elderly patients receiving $100 \%$ of the prescribed radiotherapy dose. These findings are comparable with the results of Haehl et al. in a study on 246 elderly HNSCC patients who received definitive or postoperative RCT [14]. Here, the authors report a two-year LRC rate of $75.5 \%$, with $86.6 \%$ of patients completing the radiotherapy as planned [14]. In the present study, we found that elderly patients had node-negative disease more often. This is in line with the results of the study by Tomo et al., who reported similar findings in HNSCC patients $>60$ years of age [35]. In our study, the higher rates of tumors without nodal involvement might partly explain the excellent LRC rates in elderly patients [36]. The biological basis could be the more aggressive behavior of tumors in younger patients [37]. De Oliveira et al. found a higher expression of vascular endothelial growth factor-c in young patients with tongue cancers and hypothesized that this may play a role in age-dependent tumor behavior [37]. In summary, the excellent LRC and radiotherapy completion rates indicate that radiotherapy can be safely and effectively delivered after tumor resection in elderly patients with HNSCC. 
Moreover, we found no difference in distant control (DC, five-year overall rate of $81.6 \%$ ). The rates of DC were high for both younger (five-year, $81.4 \%$ ) and elderly patients (5-year, 83.9\%). Ahn et al. found comparable five-year DC rates of more than $80 \%$ in patients $\geq 70$ years of age receiving definitive RCT for HNSCC [38]. In our study, these excellent tumor-related outcomes (LRC and DC) were achieved despite a smaller number of elderly patients receiving concomitant systemic treatment compared to the younger cohort. The careful use of concomitant systemic treatment in postoperative RCT of HNSCC was previously reported by Giacalone et al. [39]. Moreover, in the present study, concomitant systemic treatment could not be completed as planned in more elderly patients $(54.8 \%)$ than younger patients (37.5\%) (albeit not reaching statistical significance with a $p$-value of 0.07.). However, the missing information on total chemotherapy doses represents an important limitation. It should be mentioned that the major clinical trials which defined the standards for the use of concomitant systemic treatment in postoperative RCT for patients with HNSCC do not adequately reflect the elderly patient population. Bernier et al. excluded patients over 70 years [3]. In the study by Cooper et al., only $5 \%$ of patients were $\geq 70$ years of age [4]. At the same time, elderly patients are at increased risk of side effects associated with systemic treatment (e.g., due to the age-related decrease in renal function when using cisplatin $[40,41]$ ). In summary, our study underlines that systemic treatment is a reasonable option in elderly patients, as stated by previous authors [42]. However, the indication should be carefully considered on an individual basis [42]. When comparing elderly patients treated with radiotherapy alone vs. elderly patients treated with RCT, we found no differences in toxicities, OS, TTR and LRC, possibly due to the low number of patients. As previous authors stated, cisplatin dose and schedule should be adopted to the specific clinical condition [38]. For example, daily low dose cisplatin can be an option in patients with relative contraindications for cisplatin (e.g., advanced age, reduced organ function) $[28,43,44]$. In our study, this regimen was used in $50 \%$ of the elderly patients.

Next, we found that patients $\geq 70$ years experienced significantly worse overall survival (OS) and progression-free survival (PFS) than younger patients. The survival rate in patients $<70$ years was more than twice as good as in elderly patients (five-year OS, $68.7 \%$ vs. $33.8 \%$ ). The lower survival rate in elderly patients can be attributed to the generally reduced life expectancy and to the higher prevalence of comorbidities [14]. In the present study, $98.1 \%$ of the elderly patients presented with a Charlson Cormorbidity Index of $4-7$, which is associated with a 10 -year survival rate from $0.01 \%$ (Index $=7)$ to $53.4 \%$ (Index $=4$ ) [45]. However, due to the retrospective design of the present study, the causes of death were not systematically recorded. This represents a relevant limitation of the study. Nevertheless, the poor survival outcomes in patients $\geq 70$ years highlight the need for thorough discussion of multimodal treatment options in this patient group [46].

In the present study, elderly patients experienced RCT-associated mucositis and dermatitis less frequently than younger patients. The careful use of concomitant systemic treatment in these patients might explain the lower rates of acute toxicities [47]. However, Müller von der Grün et al. and Singh et al. found no differences in the rates of acute toxicities of RCT when comparing younger and older HNSCC patients [48,49]. The heterogeneous results might be attributed to the fact that the studies on elderly patients only included a limited number of patients $[14,48,49]$. Furthermore, the studies differ in patient selection and radiotherapy technique [14,48,49]. Haehl et al. reported that $\geq$ grade 3 dermatitis affected $19 / 246$ patients $(7.8 \%)$ and that $\geq$ grade 3 mucositis affected $46 / 246$ patients $(18.7 \%)$ after treatment with 3D-conformal radiotherapy or IMRT (here, the proportion of patients was not further specified with regard to technique) [14]. Müller von der Grün et al. reported $\geq$ grade 3 dermatitis for $15 \%$ of the elderly patients and $\geq$ grade 3 mucositis for $49 \%$ of the elderly patients ( $\geq 70$ years) [48]. Here, IMRT was used in $120 / 158$ patients $(75.9 \%)$ and $3 \mathrm{D}$-conformal radiotherapy was used in 38/158 patients $(24.1 \%)$ [48]. In the present study, all patients were treated with either IMRT or VMAT. This might explain the lower rates of $\geq$ grade 3 dermatitis (elderly, 1.9\%) and $\geq$ grade 3 mucositis (elderly, 9.6\%) when compared to the aforementioned studies. This indicates that modern radiotherapy 
techniques are important in effectively treating elderly HNSCC patients with, at the same time, moderate rates of acute toxicities $[8,50]$.

\section{Conclusions}

Locally advanced HNSCC are often managed with surgery followed by postoperative RCT. With the general increase in life expectancy, the proportion of elderly patients with HNSCC is expected to grow rapidly. Until now, a deeper understanding of specific management strategies for these patients in clinical routines was lacking. In the present study, we compared elderly patients ( $\geq 70$ years) and younger patients treated with postoperative RCT for HNSCC. All patients were treated with modern radiotherapy techniques (IMRT/VMAT). Patients $\geq 70$ years of age had more comorbidities. Additionally, elderly patients less frequently received concomitant systemic treatment. The rates of RCT-associated mucositis and dermatitis were lower in patients $\geq 70$ years. Elderly patients had significantly worse overall survival and progression-free survival. Locoregional and distant control were comparable in elderly and younger patients. In conclusion, postoperative RCT is a safe and effective treatment option in patients $\geq 70$ years. In light of comorbidities and poor overall survival rates, benefits and harms of radiotherapy and concomitant systemic treatment should be weighed carefully. When exclusively applying up-to-date radiotherapy techniques with, at the same time, careful use of concomitant systemic therapy, favorable acute toxicity profiles are achieved.

Supplementary Materials: The following are available online at https: / www.mdpi.com/article / 10.3390 / cancers13143384/s1, Table S1: Comparison of toxicities in patients $\geq 70$ years of age, radiotherapy alone (RT) vs. radiochemotherapy (RCT). Figure S1: Comparison of overall survival (OS) in patients $\geq 70$ years of age, radiotherapy alone (RT) vs. radiochemotherapy (RCT). Figure S2: Comparison of time to recurrence (TTR) in patients $\geq 70$ years of age, radiotherapy alone (RT) vs. radiochemotherapy (RCT). Figure S3: Comparison of locoregional control (LRC) in patients $\geq 70$ years of age, radiotherapy alone (RT) vs. radiochemotherapy (RCT).

Author Contributions: Conceptualization, M.L., C.P., M.G., M.A.S., S.R. and L.H.D.; Data curation, M.L., C.P., J.P. and Y.P.; Formal analysis, M.L., C.P., Y.P., M.A.S. and L.H.D.; Investigation, M.L., C.P., J.P. and L.H.D.; Project administration, M.L., M.G., S.R. and L.H.D.; Resources, S.R.; Supervision, M.L., M.A.S., S.R. and L.H.D.; Visualization, M.L. and L.H.D.; Writing—original draft, M.L. and L.H.D.; Writing—review \& editing, M.L., C.P., M.G., J.P., Y.P., M.A.S., S.R. and L.H.D. All authors have read and agreed to the published version of the manuscript.

Funding: The authors received no specific funding for this work.

Institutional Review Board Statement: This retrospective study was authorized by the local ethic committee (University Medical Center Göttingen, code 6/1/21).

Informed Consent Statement: Due to the retrospective type of study, an additional informed consent was not necessary.

Data Availability Statement: The datasets generated during and/or analyzed during the current study are available from the corresponding author on reasonable request.

Conflicts of Interest: The authors declare no conflict of interest.

\section{References}

1. Johnson, D.E.; Burtness, B.; Leemans, C.R.; Lui, V.W.Y.; Bauman, J.E.; Grandis, J.R. Head and neck squamous cell carcinoma. Nat. Rev. Dis. Prim. 2020, 6, 1-22. [CrossRef]

2. Bernier, J.; Cooper, J.S.; Pajak, T.F.; Ir, M.V.G.; Bourhis, J.; Forastiere, A.; Ozsahin, E.M.; Jacobs, J.R.; Jassem, J.; Ang, K.-K.; et al. Defining risk levels in locally advanced head and neck cancers: A comparative analysis of concurrent postoperative radiation plus chemotherapy trials of the EORTC (\#22931) and RTOG (\#9501). Head Neck 2005, 27, 843-850. [CrossRef]

3. Bernier, J.; Domenge, C.; Ozsahin, M.; Matuszewska, K.; Lefèbvre, J.-L.; Greiner, R.H.; Giralt, J.; Maingon, P.; Rolland, F.; Bolla, M.; et al. Postoperative Irradiation with or without Concomitant Chemotherapy for Locally Advanced Head and Neck Cancer. N. Engl. J. Med. 2004, 350, 1945-1952. [CrossRef] 
4. Cooper, J.S.; Pajak, T.F.; Forastiere, A.A.; Jacobs, J.; Campbell, B.; Saxman, S.B.; Kish, J.A.; Kim, H.E.; Cmelak, A.J.; Rotman, M.; et al. Postoperative Concurrent Radiotherapy and Chemotherapy for High-Risk Squamous-Cell Carcinoma of the Head and Neck. N. Engl. J. Med. 2004, 350, 1937-1944. [CrossRef]

5. Cooper, J.S.; Zhang, Q.; Pajak, T.F.; Forastiere, A.A.; Jacobs, J.; Saxman, S.B.; Kish, J.A.; Kim, H.E.; Cmelak, A.J.; Rotman, M.; et al. Long-term Follow-up of the RTOG 9501/Intergroup Phase III Trial: Postoperative Concurrent Radiation Therapy and Chemotherapy in High-Risk Squamous Cell Carcinoma of the Head and Neck. Int. J. Radiat. Oncol. 2012, 84, $1198-1205$. [CrossRef] [PubMed]

6. Ghosh-Laskar, S.; Yathiraj, P.H.; Dutta, D.; Rangarajan, V.; Purandare, N.C.; Gupta, T.; Budrukkar, A.; Murthy, V.; Kannan, S.; Agarwal, J.P. Prospective randomized controlled trial to compare 3-dimensional conformal radiotherapy to intensity-modulated radiotherapy in head and neck squamous cell carcinoma: Long-term results. Head Neck 2016, 38, E1481-E1487. [CrossRef] [PubMed]

7. Gupta, T.; Agarwal, J.; Jain, S.; Phurailatpam, R.; Kannan, S.; Ghosh-Laskar, S.; Murthy, V.; Budrukkar, A.; Dinshaw, K.; Prabhash, K.; et al. Three-dimensional conformal radiotherapy (3D-CRT) versus intensity modulated radiation therapy (IMRT) in squamous cell carcinoma of the head and neck: A randomized controlled trial. Radiother. Oncol. 2012, 104, 343-348. [CrossRef]

8. Van Der Veen, J.; Nuyts, S. Can Intensity-Modulated-Radiotherapy Reduce Toxicity in Head and Neck Squamous Cell Carcinoma? Cancers 2017, 9, 135. [CrossRef] [PubMed]

9. Johansen, J.; Eriksen, J.G.; on behalf of the Academy of Geriatric Cancer Research (AgeCare). Trends in cancer of the head and neck in the elderly in Denmark, 1980-2012. Acta Oncol. 2016, 55, 13-18. [CrossRef]

10. Sarris, E.G.; Harrington, K.J.; Saif, M.W.; Syrigos, K.N. Multimodal treatment strategies for elderly patients with head and neck cancer. Cancer Treat. Rev. 2014, 40, 465-475. [CrossRef]

11. Noronha, V.; Joshi, A.; Patil, V.M.; Agarwal, J.; Ghosh-Laskar, S.; Budrukkar, A.; Murthy, V.; Gupta, T.; D'Cruz, A.K.; Banavali, S.; et al. Once-a-Week Versus Once-Every-3-Weeks Cisplatin Chemoradiation for Locally Advanced Head and Neck Cancer: A Phase III Randomized Noninferiority Trial. J. Clin. Oncol. 2018, 36, 1064-1072. [CrossRef]

12. Guigay, J.; Aupérin, A.; Fayette, J.; Saada-Bouzid, E.; Lafond, C.; Taberna, M.; Geoffrois, L.; Martin, L.; Capitain, O.; Cupissol, D.; et al. Cetuximab, docetaxel, and cisplatin versus platinum, fluorouracil, and cetuximab as first-line treatment in patients with recurrent or metastatic head and neck squamous-cell carcinoma (GORTEC 2014-01 TPExtreme): A multicentre, open-label, randomised, phase 2 trial. Lancet Oncol. 2021, 22, 463-475. [CrossRef]

13. Shia, B.-C.; Qin, L.; Lin, K.-C.; Fang, C.-Y.; Tsai, L.-L.; Kao, Y.-W.; Wu, S.-Y. Outcomes for Elderly Patients Aged 70 to 80 Years or Older with Locally Advanced Oral Cavity Squamous Cell Carcinoma: A Propensity Score-Matched, Nationwide, Oldest Old Patient-Based Cohort Study. Cancers 2020, 12, 258. [CrossRef]

14. Haehl, E.; Rühle, A.; David, H.; Kalckreuth, T.; Sprave, T.; Stoian, R.; Becker, C.; Knopf, A.; Grosu, A.-L.; Nicolay, N.H. Radiotherapy for geriatric head-and-neck cancer patients: What is the value of standard treatment in the elderly? Radiat. Oncol. 2020, 15, 1-12. [CrossRef]

15. Maggiore, R.; Zumsteg, Z.S.; BrintzenhofeSzoc, K.; Trevino, K.M.; Gajra, A.; Korc-Grodzicki, B.; Epstein, J.B.; Bond, S.M.; Parker, I.; Kish, J.A.; et al. The Older Adult With Locoregionally Advanced Head and Neck Squamous Cell Carcinoma: Knowledge Gaps and Future Direction in Assessment and Treatment. Int. J. Radiat. Oncol. 2017, 98, 868-883. [CrossRef]

16. Machiels, J.-P.; Leemans, C.R.; Golusinski, W.; Grau, C.; Licitra, L.; Gregoire, V. Squamous cell carcinoma of the oral cavity, larynx, oropharynx and hypopharynx: EHNS-ESMO-ESTRO Clinical Practice Guidelines for diagnosis, treatment and follow-up. Ann. Oncol. 2020, 31, 1462-1475. [CrossRef] [PubMed]

17. Grégoire, V.; Lefebvre, J.-L.; Licitra, L.; Felip, E. Squamous cell carcinoma of the head and neck: EHNS-ESMO-ESTRO Clinical Practice Guidelines for diagnosis, treatment and follow-up. Ann. Oncol. 2010, 21, v184-v186. [CrossRef] [PubMed]

18. Leitlinienprogramm Onkologie. S3-Leitlinie: Diagnostik, Therapie und Nachsorge des Larynxkarzinoms. Available online: https:/ / www.leitlinienprogramm-onkologie.de/leitlinien/larynxkarzinom/ (accessed on 5 April 2021).

19. Leitlinienprogramm Onkologie. S3-Leitlinie: Diagnostik und Therapie des Mundhöhlenkarzinoms. Available online: https: //www.leitlinienprogramm-onkologie.de/leitlinien/mundhoehlenkarzinom/ (accessed on 5 April 2021).

20. Beschel, L.M.; Leu, M.; Reichardt, S.D.; Rave-Fränk, M.; Schirmer, M.A.; Stadelmann, C.; Canis, M.; Wolff, H.A.; Reichardt, H.M. $\mathrm{T}$ cell abundance in blood predicts acute organ toxicity in chemoradiotherapy for head and neck cancer. Oncotarget 2016, 7, 65902-65915. [CrossRef] [PubMed]

21. Grégoire, V.; Evans, M.; Le, Q.-T.; Bourhis, J.; Budach, V.; Chen, A.; Eisbruch, A.; Feng, M.; Giralt, J.; Gupta, T.; et al. Delineation of the primary tumour Clinical Target Volumes (CTV-P) in laryngeal, hypopharyngeal, oropharyngeal and oral cavity squamous cell carcinoma: AIRO, CACA, DAHANCA, EORTC, GEORCC, GORTEC, HKNPCSG, HNCIG, IAG-KHT, LPRHHT, NCIC CTG, NCRI, NRG Oncology, PHNS, SBRT, SOMERA, SRO, SSHNO, TROG consensus guidelines. Radiother. Oncol. 2018, $126,3-24$. [CrossRef]

22. Grégoire, V.; Ang, K.; Budach, W.; Grau, C.; Hamoir, M.; Langendijk, J.A.; Lee, A.; Le, Q.-T.; Maingon, P.; Nutting, C.; et al. Delineation of the neck node levels for head and neck tumors: A 2013 update. DAHANCA, EORTC, HKNPCSG, NCIC CTG, NCRI, RTOG, TROG consensus guidelines. Radiother. Oncol. 2014, 110, 172-181. [CrossRef]

23. Vorwerk, H.; Hess, C.F. Guidelines for delineation of lymphatic clinical target volumes for high conformal radiotherapy: Head and neck region. Radiat. Oncol. 2011, 6, 97. [CrossRef] [PubMed] 
24. Kirkpatrick, J.P.; van der Kogel, A.J.; Schultheiss, T.E. Radiation Dose-Volume Effects in the Spinal Cord. Int. J. Radiat. Oncol. 2010, 76, S42-S49. [CrossRef] [PubMed]

25. Deasy, J.O.; Moiseenko, V.; Marks, L.; Chao, K.C.; Nam, J.; Eisbruch, A. Radiotherapy Dose-Volume Effects on Salivary Gland Function. Int. J. Radiat. Oncol. 2010, 76, S58-S63. [CrossRef]

26. Rancati, T.; Schwarz, M.; Allen, A.M.; Feng, F.; Popovtzer, A.; Mittal, B.; Eisbruch, A. Radiation Dose-Volume Effects in the Larynx and Pharynx. Int. J. Radiat. Oncol. 2010, 76, S64-S69. [CrossRef]

27. Wolff, H.A.; Bosch, J.; Jung, K.; Overbeck, T.; Hennies, S.; Matthias, C.; Hess, C.F.; Roedel, R.M.; Christiansen, P.D.H. High-Grade Acute Organ Toxicity as Positive Prognostic Factor in Primary Radio(chemo)therapy for Locally Advanced, Inoperable Head and Neck Cancer. Strahlenther. Onkol. 2010, 186, 262-268. [CrossRef]

28. Wolff, H.A.; Overbeck, T.; Roedel, R.M.; Hermann, R.M.; Herrmann, M.K.A.; Kertesz, T.; Vorwerk, H.; Hille, A.; Matthias, C.; Hess, C.F.; et al. Toxicity of daily low dose cisplatin in radiochemotherapy for locally advanced head and neck cancer. J. Cancer Res. Clin. Oncol. 2008, 135, 961-967. [CrossRef] [PubMed]

29. Bonner, J.A.; Harari, P.M.; Giralt, J.; Azarnia, N.; Shin, D.M.; Cohen, R.B.; Jones, C.U.; Sur, R.; Raben, D.; Jassem, J.; et al. Radiotherapy plus Cetuximab for Squamous-Cell Carcinoma of the Head and Neck. N. Engl. J. Med. 2006, 354, 567-578. [CrossRef]

30. US Department of Health and Human Services. Common Terminology Criteria for Adverse Events (CTCAE), Version 5.0; US Department of Health and Human Services: Washington, DC, USA; Bethesda: Rockville, MD, USA, 2010. Available online: https:/ / ctep.cancer.gov/protocoldevelopment/electronic_applications/docs/ctcae_v5_quick_reference_5x7.pdf (accessed on 6 April 2021).

31. Rubin, P.; Constine, L.S.; Fajardo, L.F.; Phillips, T.L.; Wasserman, T.H. Overview: Late effects of normal tissues (LENT) scoring system. Int. J. Radiat. Oncol. 1995, 31, 1041-1042. [CrossRef]

32. Gross, A.; Ziepert, M.; Scholz, M. KMWin-A Convenient Tool for Graphical Presentation of Results from Kaplan-Meier Survival Time Analysis. PLoS ONE 2012, 7, e38960. [CrossRef]

33. Lichtman, S.M.; Brain, E. The International Society of Geriatric Oncology conference: Paris 2011. Aging Heal. 2012, 8, 123-126. [CrossRef]

34. SIOG: International Society of Geriatric Oncology. Defining the Elderly. Available online: http://siog.org/content/definingelderly (accessed on 8 April 2021).

35. Tomo, S.; Neto, S.; Collado, F.; Sundefeld, M.; Bernabé, D.; Biasoli, Ér.; Miyahara, G. Head and neck squamous cell carcinoma in young patients: A 26-year clinicopathologic retrospective study in a Brazilian specialized center. Med. Oral Patol. Oral Cir. Bucal 2020, 25, e416-e424. [CrossRef] [PubMed]

36. Contreras, J.A.; Spencer, C.; DeWees, T.; Haughey, B.; Henke, L.E.; Chin, R.-I.; Paniello, R.; Rich, J.; Jackson, R.; Oppelt, P.; et al. Eliminating Postoperative Radiation to the Pathologically Node-Negative Neck: Long-Term Results of a Prospective Phase II Study. J. Clin. Oncol. 2019, 37, 2548-2555. [CrossRef] [PubMed]

37. Moura, J.; Câmara, A.C.D.S.M.; Nonaka, C.; Pinto, L.P.; De Souza, L.B. Immunohistochemical comparative analysis of lymphatic vessel density and VEGF-C expression in squamous cell carcinomas of the tongue between young and old patients. Pathol. Res. Pr. 2016, 212, 1095-1101. [CrossRef]

38. Ahn, D.; Lee, G.J.; Sohn, J.H.; Lee, J.E. Phase II trial of individualized/dynamic cisplatin regimens for definitive concurrent chemoradiation therapy in patients with head and neck squamous cell carcinoma. Cancer Med. 2020, 9, 9256-9265. [CrossRef]

39. Giacalone, N.J.; Qureshi, M.M.; Mak, K.S.; Kirke, D.; Patel, S.A.; Shah, B.A.; Salama, A.R.; Jalisi, S.; Truong, M.T. Adjuvant chemoradiation does not improve survival in elderly patients with high-risk resected head and neck cancer. Laryngoscope 2018, 128, 831-840. [CrossRef] [PubMed]

40. Wang, X.; Bonventre, J.V.; Parrish, A.R. The Aging Kidney: Increased Susceptibility to Nephrotoxicity. Int. J. Mol. Sci. 2014, 15, 15358-15376. [CrossRef]

41. Hurria, A.; Togawa, K.; Mohile, S.G.; Owusu, C.; Klepin, H.D.; Gross, C.P.; Lichtman, S.; Gajra, A.; Bhatia, S.; Katheria, V.; et al. Predicting Chemotherapy Toxicity in Older Adults With Cancer: A Prospective Multicenter Study. J. Clin. Oncol. 2011, 29, 3457-3465. [CrossRef]

42. Szturz, P.; Vermorken, J.B. Treatment of Elderly Patients with Squamous Cell Carcinoma of the Head and Neck. Front. Oncol. 2016, 6, 199. [CrossRef]

43. Szturz, P.; Wouters, K.; Kiyota, N.; Tahara, M.; Prabhash, K.; Noronha, V.; Adelstein, D.; Van Gestel, D.; Vermorken, J.B. Low-Dose vs. High-Dose Cisplatin: Lessons Learned From 59 Chemoradiotherapy Trials in Head and Neck Cancer. Front. Oncol. 2019, 9, 86. [CrossRef]

44. Ahn, M.-J.; D'Cruz, A.; Vermorken, J.B.; Chen, J.-P.; Chitapanarux, I.; Dang, H.Q.T.; Guminski, A.; Kannarunimit, D.; Lin, T.-Y.; Ng, W.T.; et al. Clinical recommendations for defining platinum unsuitable head and neck cancer patient populations on chemoradiotherapy: A literature review. Oral Oncol. 2016, 53, 10-16. [CrossRef]

45. MDApp. Charlson Comorbidity Index Calculator. Available online: https://www.mdapp.co/charlson-comorbidity-index-ccicalculator-131/ (accessed on 9 April 2021).

46. Moye, V.A.; Chandramouleeswaran, S.; Zhao, N.; Muss, H.B.; Weissler, M.C.; Hayes, D.N.; Zevallos, J.P. Elderly Patients with Squamous Cell Carcinoma of the Head and Neck and the Benefit of Multimodality Therapy. Oncologist 2015, 20, 159-165. [CrossRef] [PubMed] 
47. Sharma, A.; Mohanti, B.K.; Thakar, A.; Bahadur, S.; Bhasker, S. Concomitant chemoradiation versus radical radiotherapy in advanced squamous cell carcinoma of oropharynx and nasopharynx using weekly cisplatin: A phase II randomized trial. Ann. Oncol. 2010, 21, 2272-2277. [CrossRef] [PubMed]

48. Von Der Grün, J.M.; Martin, D.; Stöver, T.; Ghanaati, S.; Rödel, C.; Balermpas, P. Chemoradiotherapy as Definitive Treatment for Elderly Patients with Head and Neck Cancer. Biomed Res. Int. 2018, 2018, 1-9. [CrossRef] [PubMed]

49. Singh, G.; Noronha, V.; Patil, V.; Menon, N.; Joshi, A.; Prabhash, K. Safety and efficacy of concurrent chemoradiotherapy for head and neck cancers in younger versus older patients: Post hoc analysis of a randomized control trial. Ann. Oncol. 2020, 31 , S1351. [CrossRef]

50. Brown, M.L.; Glanzmann, C.; Huber, G.; Bredell, M.; Rordorf, T.; Studer, G. IMRT/VMAT for malignancies in the head-and-neck region: Outcome in patients aged 80. Strahlenther. Onkol. 2016, 192, 526-536. [CrossRef] 